\title{
AXL and GAS6 co-expression in lung adenocarcinoma as a prognostic classifier
}

\author{
MASAHIRO SEIKE ${ }^{1}$, CHEOL-HONG KIM ${ }^{1,2}$, FENFEI ZOU ${ }^{1}$, RINTARO NORO ${ }^{1}$, MIKA CHIBA ${ }^{1}$, \\ ARIMI ISHIKAWA $^{3}$, SHINOBU KUNUGI ${ }^{3}$, KAORU KUBOTA ${ }^{1}$ and AKIHIKO GEMMA ${ }^{1}$ \\ ${ }^{1}$ Department of Pulmonary Medicine and Oncology, Graduate School of Medicine, Nippon Medical School, \\ Tokyo 113-8603, Japan; ${ }^{2}$ Department of Internal Medicine, Respiratory Health Center, Hallym University \\ Dongtan Sacred Heart Hospital, Gyeonggi 18450, Republic of Korea; ${ }^{3}$ Department of Analytic Human \\ Pathology, Graduate School of Medicine, Nippon Medical School, Tokyo 113-8603, Japan
}

Received October 17, 2016; Accepted March 30, 2017

DOI: $10.3892 /$ or.2017.5594

\begin{abstract}
AXL, a receptor tyrosine kinase implicated in cell survival, proliferation, and migration, is also associated with acquired resistance to epidermal growth factor receptor (EGFR) tyrosine kinase inhibitor therapy. However, its prognostic significance in lung adenocarcinoma (AD) remains unclear. We therefore evaluated the prognostic significance of the expression of AXL and/or its ligand, growth arrestspecific 6 (GAS6), in completely resected lung AD. We evaluated the relationship between AXL, GAS6, and vimentin expression, as determined by immunohistochemistry (IHC) analysis, with overall survival and disease-free survival in 113 patients with stages I-III lung AD. Protein expression was also assayed using western blot analysis in 10 lung $\mathrm{AD}$ cell lines. AXL-positive ( $\left.\mathrm{AXL}^{+}\right)$, GAS6-positive $\left(\mathrm{GAS6}^{+}\right)$, or $\mathrm{AXL}^{+} / \mathrm{GAS6}^{+}$staining was significantly associated with vimentin-positive (vimentin ${ }^{+}$) expression. $\mathrm{AXL}^{+} / \mathrm{GAS}^{+}$and vimentin ${ }^{+}$showed a negative tendency toward an association with EGFR mutation. $\mathrm{AXL}^{+}, \mathrm{GAS}^{+}$, or $\mathrm{AXL}^{+} / \mathrm{GAS}^{+}$status significantly correlated with poor overall survival. In stage I cases, $\mathrm{AXL}^{+} / \mathrm{GAS}^{+}$status significantly correlated with poor overall survival and disease-free survival, especially in cases with wild-type EGFR. In multivariate analysis, AXL/GAS6 classifications in stage I as well as in stages I-III lung AD were found to be independent factors for poor patient outcomes. Unlike lung AD cell lines with mutant EGFR, almost all cells with wild-type EGFR showed AXL and vimentin co-expression as determined by western blotting. $\mathrm{AXL}^{+}$and $\mathrm{GAS6}^{+}$expression is relevant to a poor prognosis in resected lung AD patients at stage I. AXL/GAS6 might serve as crucial
\end{abstract}

Correspondence to: Dr Cheol-Hong Kim, Department of Internal Medicine, Respiratory Health Center, Hallym University Dongtan Sacred Heart Hospital, 7 Keunjaebong-gil, Hwaseong-si, Gyeonggi-do 18450, Republic of Korea

E-mail: kimch2002@gmail.com

Key words: AXL, GAS6, lung adenocarcinoma, prognosis, survival predictive and prognostic biomarkers and targets to identify individuals at high risk of post-operative death.

\section{Introduction}

Lung cancer is the leading cause of cancer-associated deaths worldwide, contributing to approximately 1.4 million deaths each year despite major advances in diagnostics and treatment in the last decade (1). Approximately $80 \%$ of lung cancers are classified histologically as non-small cell lung cancers (NSCLCs), of which the most common type is adenocarcinoma (AD), accounting for approximately half of all NSCLCs (2). Therapeutic strategies for lung AD patients currently focus on inhibiting target molecules or oncogenic pathways such as receptor tyrosine kinases (3-5). Unfortunately, despite initial marked responses to tyrosine kinase inhibitors (TKIs), most AD patients with oncogenic driver mutations eventually acquire resistance. Therefore, identification of predictive and prognostic biomarkers and precision medicine using the biomarkers could have a clinically significant impact on treatment strategies for lung AD patients.

Signaling by AXL, a receptor tyrosine kinase, induces the downstream activation of phosphoinositide 3-kinase (PI3K)/ AKT, signal transducer and activator of transcription 3 (STAT3), mitogen-activated protein kinase (MAPK), and nuclear factor $\kappa \mathrm{B}(6-8)$. Growth arrest-specific 6 (GAS6) is a ligand of AXL and a member of the vitamin K-dependent protein family. AXL overexpression is associated with cell survival, proliferation, invasion, migration, cell-to-cell adhesion, metastasis, and anti-apoptosis in different types of tumors $(9,10)$. In human cancers, increased expression of AXL has been observed in glioma and cancer cells of the breast, stomach and lung, and is associated with invasion and metastasis (11-14). Furthermore, recent studies revealed that AXL overexpression led to resistance to EGFR-TKI in NSCLC cells undergoing epithelial-to-mesenchymal transition (EMT), making AXL a potential therapeutic target in patients with acquired resistance to EGFR-TKIs $(15,16)$.

In this study, we examined the correlation of AXL and GAS6 expression with clinicopathologic parameters and prognoses in patients with complete lung AD resection. We 
ultimately found that the combination of AXL and GAS6 expression was useful in distinguishing those with a worse prognosis, particularly among stage I AD patients.

\section{Materials and methods}

Patients and tumor samples. We carried out a retrospective study of 113 Japanese patients who had been diagnosed with lung $\mathrm{AD}$ and had undergone complete surgical resection at Nippon Medical School Hospital between 2001 and 2009. The patients were enrolled consecutively into the cohort upon undergoing surgery. During a 5-year follow-up, overall survival was measured from the date of lung cancer surgery until the date of death, and disease-free survival (DFS) was measured from the date of surgery until relapse. All tumor samples were freshly collected during surgery, quickly snapfrozen and stored at $-80^{\circ} \mathrm{C}$. TNM staging, including $\mathrm{T}$ factor, $\mathrm{N}$ factor and tumor differentiation grade $(\mathrm{G})$, was assessed by the latest TNM staging system and by following the 7th edition of the American Joint Committee on Cancer Staging Manual (17-19). Specimens from lung AD patients were used only for immunohistochemistry (IHC) analysis. The study protocol was approved by an ethics committee review board at Nippon Medical School Hospital. Written informed consent was obtained from all patients and the specimen of the patients was inspected according to the Declaration of Helsinki 2008.

Cell culture. Ten lung AD cell lines were used in the present study: PC-9, HCC827, NCI-H1975, A549, RERF-LC-KJ, RERF-LC-MC, NCI-H441, PC-14, LC-2/ad and ABC-1. Cell lines were grown in RPMI-1640 medium (Gibco, Carlsbad, CA, USA), except ABC-1 and RERF-LCMS, which were grown in minimum essential medium Eagle (Sigma-Aldrich, St. Louis, MO, USA). All media were supplemented with $10 \%$ fetal bovine serum. The cell line, PC-14, was obtained from Immuno-Biological Laboratories (Gunma, Japan); HCC827, NCI-H441, and NCI-H1975 were obtained from the American Type Culture Collection (ATCC, Manassas, VA, USA); A549, LC-2/ad, PC-9, and RERF-LCKJ were obtained from the RIKEN BRC Cell Bank (Ibaraki, Japan); and ABC-1 and RERF-LCMS were obtained from the Japanese Collection of Research Bioresources Collection (JCRB) Cell Bank (Osaka, Japan). Of the three cell lines with activating EGFR mutations, PC-9 and NCI-HCC827 contained EGFR deletions (delE746-A750) at exon 19, and NCI-H1975 showed double mutations: L858R at exon 21 and T790M at exon 20. The other cells all had wild-type EGFR.

Detection of EGFR mutations. The PNA-LNA PCR clamp method was used to identify EGFR mutations in tissue or cytology specimens by LSI Medience Corp. (Tokyo, Japan), as previously described (20).

Immunohistochemistry. Immunohistochemistry (IHC) was consecutively performed on formalin-fixed,paraffin-embedded sections. After deparaffinization, sections were quenched for endogenous activity with $0.3 \%$ hydrogen peroxide plus absolute methanol for $20 \mathrm{~min}$. Thereafter, antigen retrieval was carried out in a $10 \mathrm{mmol} / \mathrm{l}$ citrate buffer solution ( $\mathrm{pH} 6.0$; LSI Medience Corp.) for 10 min using an autoclave. After blocking with $2 \%$ normal swine serum (Vector Laboratories Inc., Burlingame, CA, USA), sections were washed and incubated with goat anti-AXL polyclonal antibody (\#AF154, Rot: DMG0514051) and goat anti-GAS6 polyclonal antibody (\#AB885, Rot: DNH0113121; R\&D Systems Inc., Minneapolis, MN, USA), or anti-vimentin antibody (\#3932, Rot: 3; Cell Signaling Technology Inc., Danvers, MA, USA) overnight at $4^{\circ} \mathrm{C}$. After washing, slides were incubated for $30 \mathrm{~min}$ with biotinylated anti-goat antibody for AXL and GAS6, or anti-rabbit antibody for vimentin (1:200 dilution; Vector Laboratories), and treated with an avidin-biotin complex kit (Funakoshi Co., Ltd., Tokyo, Japan). Finally, slides were exposed to 3, 3'-diaminobenzidine tetrahydrochloride (Muto Pure Chemicals Co., Ltd., Tokyo, Japan), followed by counterstaining with Mayer's hematoxylin. Negative control slides were prepared by omitting the primary antibody in the above steps.

Evaluation of immunohistochemical expression of $A X L$, GAS6, and vimentin. IHC scoring was performed using a Histoscore (H-score) as previously described (21), where the staining intensity was graded as follows: 0 (none), 1 (weak), 2 (moderate), and 3 (strong). The percentage of immunoreactive positive tumor cells for AXL and GAS6 were graded as follows: $0,<10 \%$ positive cells; $1,10-25 \%$ positive cells; 2 , $25-50 \%$ positive cells; $3,50-75 \%$ positive cells; and $4, \geq 75 \%$ positive cells. The percentage of vimentin-positive tumor cells was graded differently as follows: $0,<5 \%$ positive cells; 1 , 5-30\% positive cells; $2,30-70 \%$ positive cells; and 3, $\geq 70 \%$ positive cells (22). The final $\mathrm{H}$-score was obtained by multiplying the intensity grade by the percentage grade. All slides were reviewed and scored independently by two investigators (C.-H. Kim and F. Zou) who were blinded to clinical information pertaining to patients. A tumor was defined as positive for IHC staining if the AXL $\mathrm{H}$-score $\geq 1.0$, GAS6 $\mathrm{H}$-score, $\geq 3.0$ and vimentin $\mathrm{H}$-score $\geq 1.0$; in all other cases, a tumor was defined as negative (Fig. 1).

Western blotting. Western blotting was performed as previously described $(23,24)$. Protein samples $(10 \mu \mathrm{g})$ were separated by SDS-PAGE, transferred to nitrocellulose membranes and incubated in solutions of primary antibodies: anti-AXL (\#AF154, Rot: DMG0514051), anti-GAS6 (\#AB885, Rot: DNH0113121), anti-vimentin (\#3932, Rot: 3 ) and $\beta$-actin (\#A5316, Rot: 123M4876). Anti- $\beta$-actin was obtained from Sigma-Aldrich. Anti-goat antibody for AXL and GAS6, anti-rabbit antibody for vimentin or anti-mouse antibody for $\beta$-actin were used as secondary antibodies (1:5000 dilution; Vector Laboratories). Proteins were detected with Clarity ${ }^{\mathrm{TM}}$ ECL Western Blotting Substrate (Bio-Rad Laboratories, Inc., Hercules, CA, USA) and visualized using a chemiluminescence system (GE Healthcare Japan Corp., Tokyo, Japan).

Statistical analysis. Correlations between IHC staining and clinicopathological factors were determined using the chisquare test or the Fisher's exact test. Kaplan-Meier survival curves were drawn for overall survival and DFS and compared by log-rank test. The 5-year survival rate was analyzed by the Wilcoxon rank test. Univariate and multivariate analyses were performed using the Cox proportional hazard model. All tests were two-sided, and a P-value of $<0.05$ was considered 
A

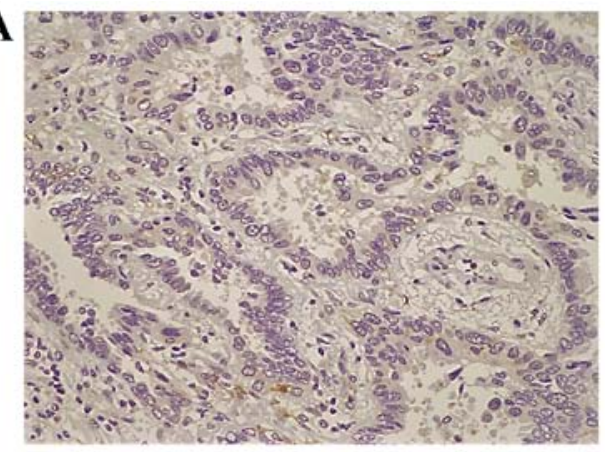

AXL staining

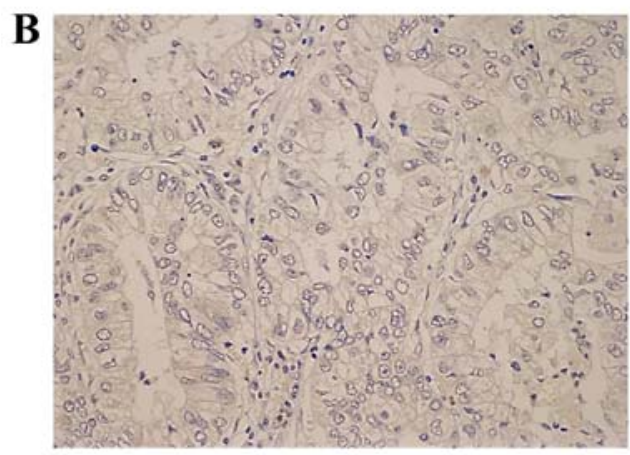

GAS6- staining

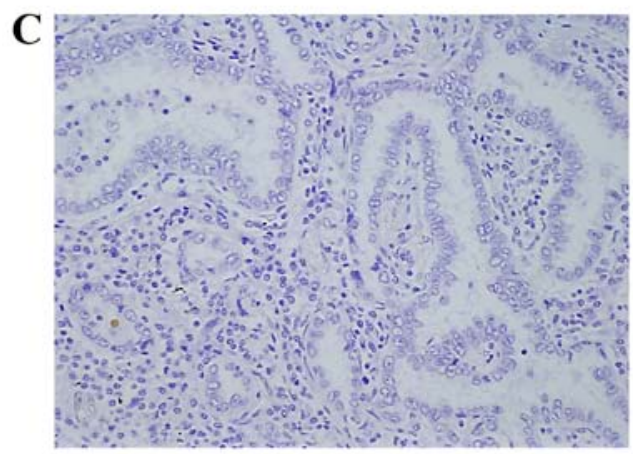

Vimentin staining

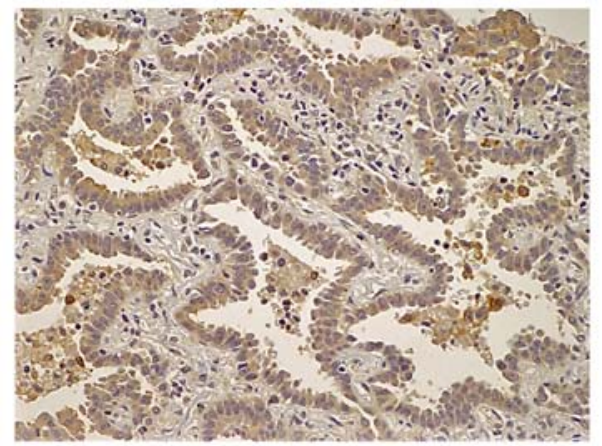

$\mathrm{AXL}^{+}$staining

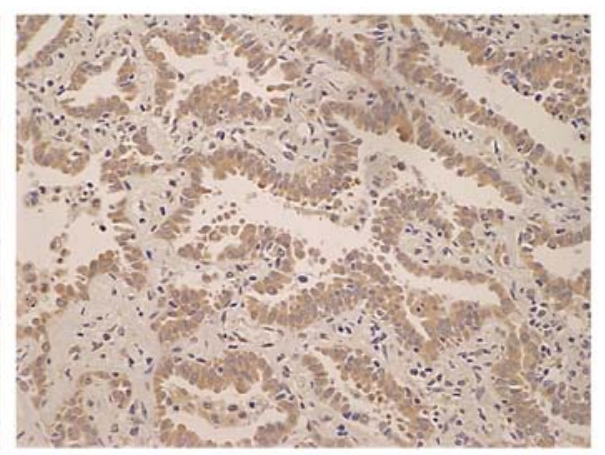

$\mathrm{GAS6}^{+}$staining

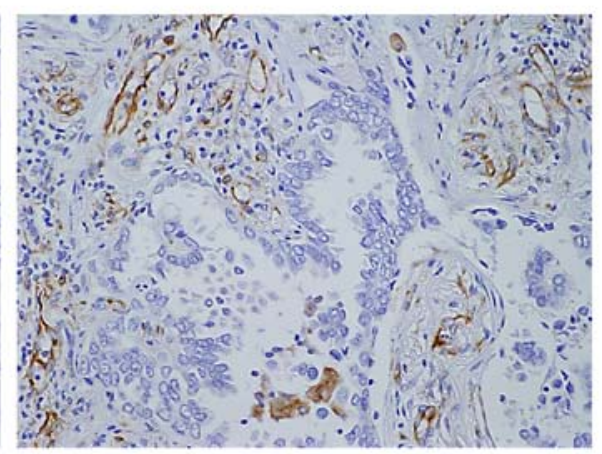

Vimentin $^{+}$staining

Figure 1. Immunohistochemical staining of lung adenocarcinoma specimens. Immunohistochemical staining for (A) AXL, (B) GAS6 and (C) vimentin, showing tumors with negative and positive staining patterns (original magnification x200).

statistically significant. Statistical analyses were performed using IBM SPSS Statistics version 21 (IBM SPSS, Inc., Armonk, NY, USA).

\section{Results}

$A X L$ and GAS6 expression in lung AD. Among 113 patients with IHC staining for AXL and GAS6 proteins, 43 (38.1\%) were positive for AXL $\left(\mathrm{AXL}^{+}\right), 38(33.6 \%)$ were positive for GAS6 $\left(\mathrm{GAS}^{+}\right)$, and $20(17.7 \%)$ were positive for both AXL and GAS6 (AXL ${ }^{+} / \mathrm{GAS6}^{+}$; Fig. 1; Table I). Associations between patient clinicopathological parameters and $\mathrm{AXL}^{+}$or $\mathrm{GAS6}^{+}$status are shown in Table II. There were no significant associations between $\mathrm{AXL}^{+}$or $\mathrm{GAS}^{+}$and parameters such as age, sex, smoking, $\mathrm{T}$ factor, $\mathrm{N}$ factor, tumor grade, postoperative recurrence, and EGFR status. The 5-year survival rates for patients who were $\mathrm{AXL}^{+}$or $\mathrm{GAS}^{+}$were significantly lower than those for AXL- or GAS6 patients (51\% vs. 75\%; $\mathrm{P}=0.028 ; 53 \%$ vs. $72 \%$; $\mathrm{P}=0.040$ ).
Association between AXL or GAS6 and vimentin expression. The overexpression of AXL and GAS6 is associated with an EMT phenotype $(15,16)$. Therefore, we evaluated vimentin expression as a mesenchymal marker. Of 113 patients, 84 were assessed by IHC assessment for vimentin. Eighteen cases (21.4\%) were vimentin positive (vimentin ${ }^{+}$; Fig. 1; Table I). A vimentin ${ }^{+}$status significantly correlated with $\mathrm{AXL}^{+}, \mathrm{GAS}^{+}$, and $\mathrm{AXL6}^{+} / \mathrm{GAS}^{+}$status $(\mathrm{P}=0.044, \mathrm{P}=0.023$ and $\mathrm{P}=0.004$, respectively; Fig. 2A-C). The frequency of vimentin ${ }^{+}$increased with the extent of $\mathrm{AXL}^{+}$or $\mathrm{GAS}^{+}$, which was highest for the $\mathrm{AXL}^{+} / \mathrm{GAS}^{+}$group (44.4\%), followed by the single-positive group $\left(\mathrm{AXL}^{+} / \mathrm{GAS6}^{-}\right.$plus $\left.\mathrm{AXL}^{-} / \mathrm{GAS6}^{+} ; 33.3 \%\right)$ and then the AXL/GAS6 group (22.2\%; $\mathrm{P}=0.006$, linear-by-linear association; Fig. 2D). With regard to EGFR status, none of the 18 patients who were vimentin ${ }^{+}$had a mutant EGFR. On the other hand, 16 (24.2\%) of 66 patients who were vimentin- showed EGFR mutations ( $\mathrm{P}=0.018$; Fig. 2E). Similarly, two (10\%) of 20 patients with $\mathrm{AXL}^{+} / \mathrm{GAS}^{+}$had a mutant EGFR, while $20(21.5 \%)$ of 93 patients in the other groups $\left(\mathrm{AXL}^{+} / \mathrm{GAS6}^{-}\right.$ 
Table I. Association between AXL and GAS6 expressions and patient characteristics.

\begin{tabular}{|c|c|c|c|c|c|c|c|}
\hline Variables & $\mathrm{N}$ & $\mathrm{AXL}^{+}$ & $\mathrm{AXL}^{-}$ & P-value & $\mathrm{GAS6}^{+}$ & GAS6- & P-value \\
\hline Total, $n=113$ & & $43(38.1)$ & $70(61.9)$ & & $38(33.6)$ & $75(66.4)$ & \\
\hline \multicolumn{8}{|l|}{ Age (years) } \\
\hline$<65$ & $41(36.3)$ & $16(37.2)$ & $25(35.7)$ & & $12(31.6)$ & $29(38.7)$ & \\
\hline$\geq 65$ & $72(63.7)$ & $27(62.8)$ & $45(64.3)$ & 0.87 & $26(68.4)$ & $46(61.3)$ & 0.46 \\
\hline \multicolumn{8}{|l|}{ Sex } \\
\hline Male & $57(50.4)$ & $24(55.8)$ & $33(47.1)$ & & $17(44.7)$ & $40(53.3)$ & \\
\hline Female & $56(49.6)$ & $19(44.2)$ & $37(52.9)$ & 0.37 & $21(55.3)$ & $35(46.7)$ & 0.39 \\
\hline \multicolumn{8}{|l|}{ Smoking $^{\mathrm{a}}$} \\
\hline Current and former smoker & $68(60.7)$ & $29(69.0)$ & $39(55.7)$ & & $22(57.9)$ & $46(62.2)$ & \\
\hline Non-smoker & $44(39.3)$ & $13(31.0)$ & $31(44.3)$ & 0.16 & $16(42.1)$ & $28(37.8)$ & 0.66 \\
\hline \multicolumn{8}{|l|}{$\mathrm{T}$ factor } \\
\hline $\mathrm{T} 1$ & $34(30.1)$ & $15(34.9)$ & $19(27.1)$ & & $13(34.2)$ & $21(28.0)$ & \\
\hline $\mathrm{T} 2-4$ & $79(69.9)$ & $28(66.1)$ & $51(72.9)$ & 0.38 & $25(65.8)$ & $54(72.0)$ & 0.50 \\
\hline \multicolumn{8}{|l|}{$\mathrm{N}$ factor } \\
\hline N0 & $78(69.0)$ & $27(62.8)$ & $51(72.9)$ & & $25(65.8)$ & $53(70.7)$ & \\
\hline N1-2 & $35(31.0)$ & $16(37.2)$ & $19(27.1)$ & 0.26 & $13(34.2)$ & $22(29.3)$ & 0.60 \\
\hline \multicolumn{8}{|l|}{ Stage } \\
\hline I & $64(56.6)$ & $24(55.8)$ & $40(57.1)$ & & $20(52.6)$ & $44(58.7)$ & \\
\hline II-III & $49(43.4)$ & $19(44.2)$ & $30(42.9)$ & 0.89 & $18(47.4)$ & $31(41.3)$ & 0.54 \\
\hline \multicolumn{8}{|l|}{ Grade } \\
\hline G1 & $34(30.1)$ & $14(32.6)$ & $20(28.6)$ & & $14(36.8)$ & $20(26.7)$ & \\
\hline $\mathrm{G} 2-3$ & $79(69.1)$ & $29(67.4)$ & $50(71.4)$ & 0.65 & $24(63.2)$ & $55(73.3)$ & 0.27 \\
\hline \multicolumn{8}{|l|}{ EGFR } \\
\hline Wild-type & $91(80.5)$ & $34(79.1)$ & $57(81.4)$ & & $34(89.5)$ & $57(76.0)$ & \\
\hline Mutant & $22(19.5)$ & $9(20.9)$ & $13(18.6)$ & 0.76 & $4(10.5)$ & $18(24.0)$ & 0.09 \\
\hline \multicolumn{8}{|l|}{ Post-operative recurrence } \\
\hline No & $60(53.1)$ & $21(48.8)$ & $39(55.7)$ & & $19(50.0)$ & $41(54.7)$ & \\
\hline Yes & $53(46.9)$ & $22(51.2)$ & $31(44.3)$ & 0.40 & $19(50.0)$ & $34(45.3)$ & 0.64 \\
\hline \multicolumn{8}{|l|}{ Vimentin $\mathrm{IHC}^{\mathrm{b}}$} \\
\hline Negative & $66(78.6)$ & $23(67.6)$ & $43(86.0)$ & & $21(65.6)$ & $45(86.5)$ & \\
\hline Positive & $18(21.4)$ & $11(32.4)$ & $7(14.0)$ & 0.044 & $11(34.4)$ & $7(13.5)$ & 0.023 \\
\hline 5-year survival rate, $\%$ & & 51 & 75 & $0.028^{\mathrm{c}}$ & 53 & 72 & $0.040^{\mathrm{c}}$ \\
\hline
\end{tabular}

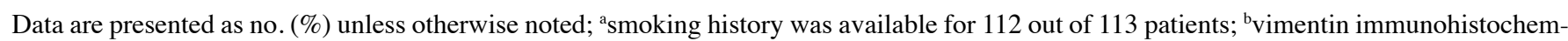
istry (IHC) was available for 84 out of 113 patients; ${ }^{\circ}$ Wilcoxon rank test.

plus AXL-/GAS6 ${ }^{+}$plus AXL-/GAS6 ${ }^{-}$) showed the presence of EGFR mutations, although the difference was not statistically significant $(\mathrm{P}=0.354$; Fig. $2 \mathrm{~F})$. This suggested that high expression levels of AXL and GAS6 were associated with vimentin overexpression and a wild-type EGFR status.

Association between AXL and/or GAS6 expression and clinical outcome. We next evaluated correlations between AXL, GAS6, vimentin expression, and patient prognosis. Overall survival was not significantly different between vimentin ${ }^{+}$ and vimentin ${ }^{-}$for stages I-III lung $\mathrm{AD}(\mathrm{P}=0.167$; data not shown). In contrast, $\mathrm{AXL}^{+}$or $\mathrm{GAS}^{+}$status was significantly associated with poor overall survival compared to $\mathrm{AXL}^{-}$or GAS6- among patients with stages I-III lung AD ( $\mathrm{P}=0.027$ and $\mathrm{P}=0.042$, respectively; Fig. $3 \mathrm{~A}$ and $\mathrm{B})$. Furthermore, patients showing $\mathrm{AXL}^{+} / \mathrm{GAS}^{+}$were also significantly associated with poor overall survival compared to $\mathrm{AXL}^{-} / \mathrm{GAS}^{-}$or other groups (AXL ${ }^{+} \mathrm{GAS}^{-}$plus AXL $/ \mathrm{GAS6}^{+}$plus AXL/GAS6; $\mathrm{P}=0.004$ and $\mathrm{P}=0.008$, respectively; Fig. $3 \mathrm{C}$ and $\mathrm{D}$ ); however, there was no significant association between $\mathrm{AXL}^{+} / \mathrm{GAS}^{+}$ and $\mathrm{AXL}^{+} / \mathrm{GAS}^{-}$plus $\mathrm{AXL}^{-} / \mathrm{GAS}^{+}(\mathrm{P}=0.094$; Fig. 3C). These results suggested that AXL and GAS6 co-expression 
$\mathbf{A}$
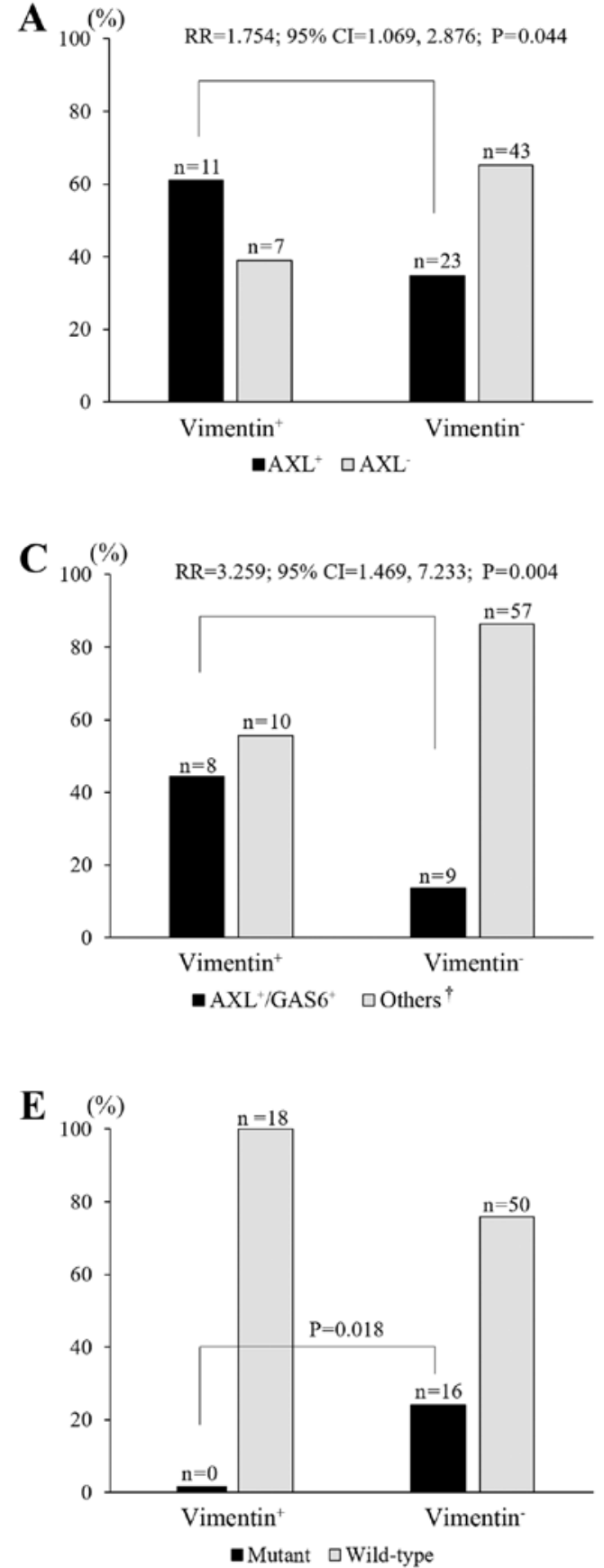
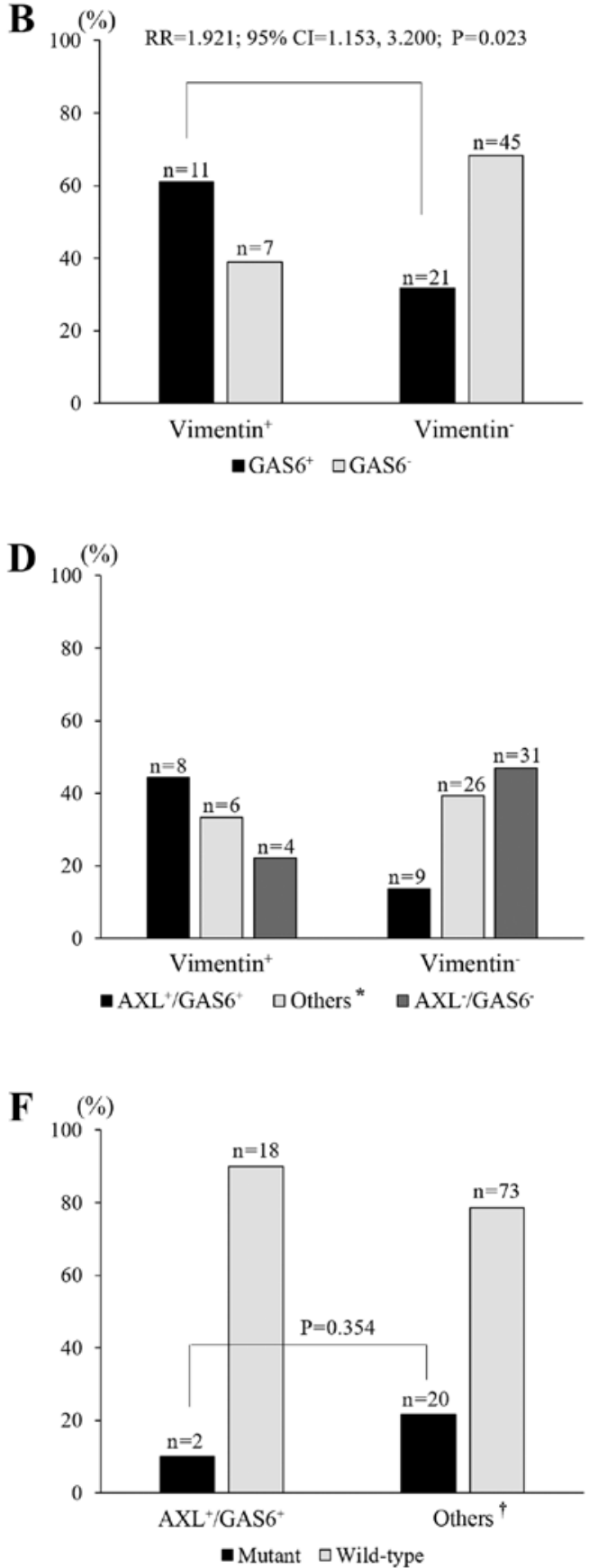

Figure 2. Relationships between AXL and/or GAS6 and vimentin expression, and of AXL/GAS6 and vimentin expression with EGFR mutation status. (A-C) The frequency of $\mathrm{AXL}^{+}$[relative risk $\left.(\mathrm{RR})=1.754, \mathrm{P}=0.044\right]$, $\mathrm{GAS}^{+}(\mathrm{RR}=1.921, \mathrm{P}=0.023)$, and $\mathrm{AXL}^{+} / \mathrm{GAS6}^{+}(\mathrm{RR}=3.259, \mathrm{P}=0.004)$ correlated with vimentin ${ }^{+}$expression. (D) The frequency of vimentin ${ }^{+}$increased with the co-expression of $\mathrm{AXL}^{+} / \mathrm{GAS}^{+}$, followed by the 'others' category and AXL/GAS6 ( $\mathrm{P}=0.006$, linear-by-linear association). (E) Mutant EGFR was lacking in vimentin ${ }^{+}$cases $\left(\mathrm{P}=0.018\right.$, versus the vimentin ${ }^{-}$group). ( $\left.\mathrm{F}\right)$ Mutant EGFR was observed in two cases $(10 \%)$ of the $\mathrm{AXL}^{+} / \mathrm{GAS}^{+}$group and in 10 cases $(22 \%)$ of the 'others' group $(\mathrm{P}=0.354)$. *, 'others' includes the single-positive groups

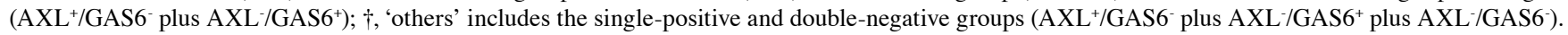

$\left(\mathrm{AXL}^{+} / \mathrm{GAS}^{+}\right)$was associated with a poor prognosis for lung AD. Next, we investigated whether a patient's prognosis was affected by $\mathrm{AXL}^{+}$or $\mathrm{GAS6}^{+}$expression among patients stratified according to stage and EGFR status. For stage I cases, overall survival and DFS rates for $\mathrm{AXL}^{+} / \mathrm{GAS}^{+}$cases were significantly shorter than those for other cases $(\mathrm{P}=0.007$ and $\mathrm{P}=0.006$, respectively; Fig. $3 \mathrm{E}$ and $\mathrm{F}$ ). In stage I patients with wild-type EGFR, the overall survival and DFS rates for $\mathrm{AXL}^{+} / \mathrm{GAS}^{+}$patients were also significantly shorter than those for the other patients $(\mathrm{P}=0.0001$ and $\mathrm{P}=0.0004$, respectively; Fig. 3G and $\mathrm{H}$ ). In contrast, $\mathrm{AXL}^{+} / \mathrm{GAS}^{+}$as a negative prognostic factor was not observed in stage I patients with mutant EGFR (data not shown). Thus, AXL and GAS6 expression in combination significantly correlated with a poor outcome for stage I lung AD and an EGFR wild-type status.

The impact of AXL/GAS6 expression on lung AD patient survival. We finally evaluated whether the prognostic ability of $\mathrm{AXL}^{+} / \mathrm{GAS}^{+}{ }^{+}$was affected by underlying clinicopathological covariates using univariate and multivariate Cox regression 

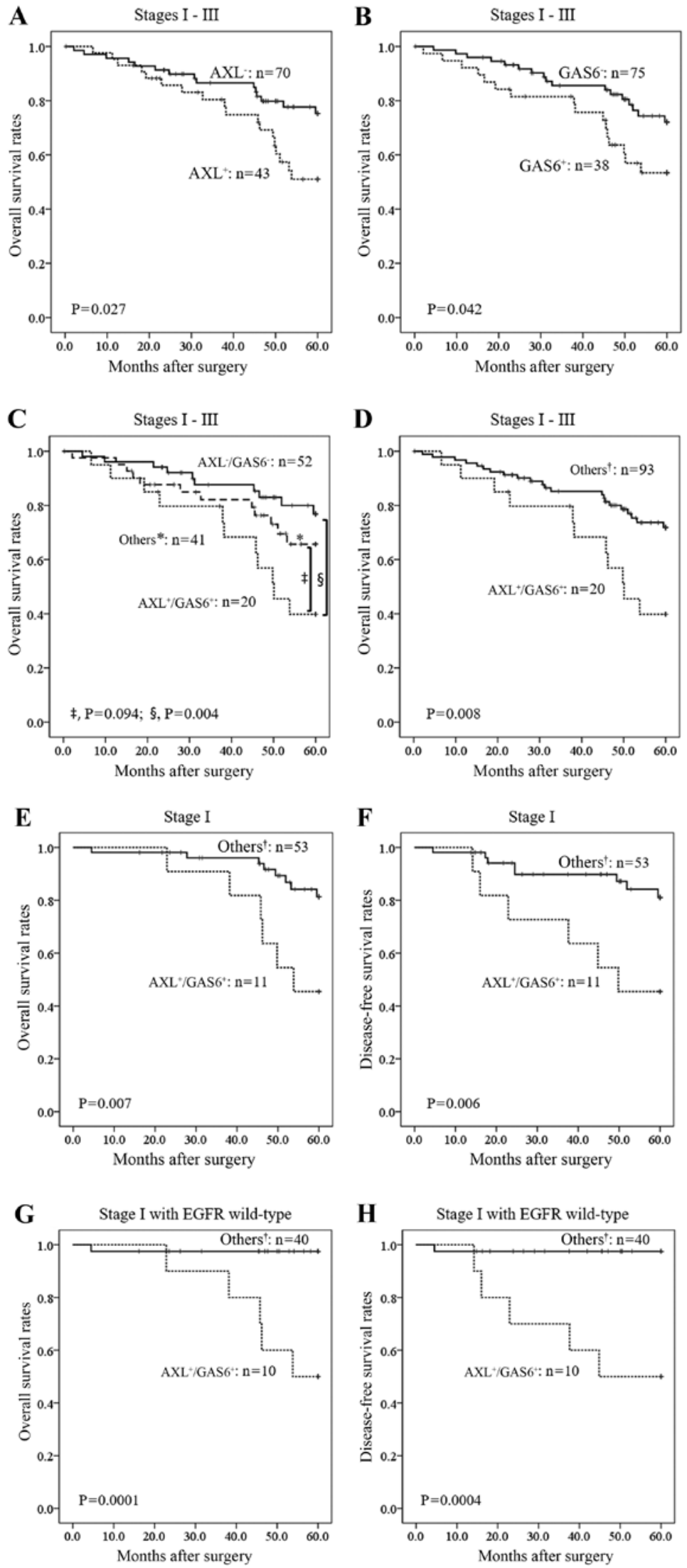

Figure 3. Kaplan-Meier analyses of overall survival and disease-free survival. (A and B) In patients with stages I-III AD, a significant difference in overall survival was found between $\mathrm{AXL}^{+}$and $\mathrm{AXL}$ - groups $(\mathrm{P}=0.027)$ and between $\mathrm{GAS}^{+}$and $\mathrm{GAS6}^{-}$groups $(\mathrm{P}=0.042)$. (C) A significant difference in overall survival was found between $\mathrm{AXL}^{+} / \mathrm{GAS6}^{+}$and $\mathrm{AXL}^{-} / \mathrm{GAS6}^{-}$groups $(\mathrm{P}=0.004)$. (D) A significant difference in overall survival was found between the $\mathrm{AXL}^{+} / \mathrm{GAS6}^{+}$ and 'others' groups $(\mathrm{P}=0.008)$. ( $\mathrm{E}$ and $\mathrm{F}$ ) In stage I patients, significant differences in overall survival and disease-free survival (DFS) rates existed between the $\mathrm{AXL}^{+} / \mathrm{GAS6}^{+}$and 'others' groups ( $\mathrm{P}=0.007$ and $\mathrm{P}=0.006$, respectively). ( $\mathrm{G}$ and $\left.\mathrm{H}\right) \mathrm{In}$ stage $\mathrm{I}$ with wild-type EGFR subgroup, significant differences in overall survival and DFS rates were shown between the $\mathrm{AXL}^{+} / \mathrm{GAS}^{+}$and 'others' groups $(\mathrm{P}=0.0001$ and $\mathrm{P}=0.0004$, respectively). *, 'others' includes the

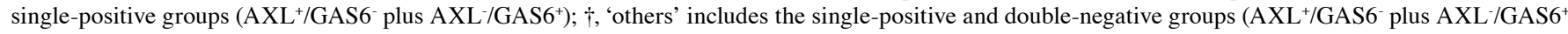
plus AXL/GAS6-). 
Table II. Univariate and multivariate Cox proportional hazards models of factors associated with death in stages I-III and stage I patients.

\begin{tabular}{|c|c|c|c|c|c|c|c|}
\hline \multirow[b]{2}{*}{ Characteristics } & \multirow{2}{*}{$\begin{array}{c}\text { Comparison } \\
\text { Reference vs. risk group }\end{array}$} & \multicolumn{3}{|c|}{ Univariate analysis } & \multicolumn{3}{|c|}{ Multivariate analysis } \\
\hline & & HR & $95 \% \mathrm{CI}$ & $\mathrm{P}$-value & HR & $95 \% \mathrm{CI}$ & $\mathrm{P}$-value \\
\hline \multicolumn{8}{|l|}{ Stages I-III cases $(n=113)$} \\
\hline Age (years) & $<65$ vs. $\geq 65$ & 0.75 & $0.38,1.49$ & 0.41 & & & \\
\hline Sex & Male vs. female & 0.90 & $0.46,1.79$ & 0.77 & & & \\
\hline Smoking & Non vs. smoker & 0.71 & $0.36,1.41$ & 0.33 & & & \\
\hline $\mathrm{T}$ factor & T1 vs. T2-4 & 0.94 & $0.46,1.94$ & 0.87 & & & \\
\hline $\mathrm{N}$ factor & N0 vs. N1-2 & 2.94 & $1.47,5.90$ & 0.002 & 1.57 & $0.50,4.94$ & 0.44 \\
\hline p-stage & I vs. II-III & 2.61 & $1.30,5.24$ & 0.007 & 1.87 & $0.61,5.78$ & 0.28 \\
\hline Grade & G1 vs. G2+3 & 0.92 & $0.44,1.89$ & 0.81 & & & \\
\hline EGFR & Wild-type vs. mutant & 2.05 & $0.99,4.24$ & 0.05 & & & \\
\hline Vimentin IHC & Negative vs. positive & 0.44 & $0.13,1.46$ & 0.18 & & & \\
\hline AXL/GAS6 classification & The others ${ }^{\mathrm{a}}$ vs. AXL ${ }^{+} / \mathrm{GAS6}^{+}$ & 2.56 & $1.24,5.29$ & 0.011 & 2.45 & $1.16,5.17$ & 0.018 \\
\hline \multicolumn{8}{|l|}{ Stage I cases $(n=64)$} \\
\hline Age (years) & $<65$ vs. $\geq 65$ & 0.80 & $0.28,2.30$ & 0.68 & & & \\
\hline Sex & Male vs. female & 1.15 & $0.40,3.28$ & 0.80 & & & \\
\hline Smoking & Non vs. smoker & 0.60 & $0.21,1.72$ & 0.34 & & & \\
\hline $\mathrm{T}$ factor & T1 (IA) vs. T2 (IB) & 0.91 & $0.32,2.62$ & 0.86 & & & \\
\hline Grade & G1 vs. G2+3 & 2.56 & $0.57,11.46$ & 0.22 & & & \\
\hline EGFR & Wild-type vs. mutant & 6.22 & $2.14,18.13$ & 0.001 & 9.30 & $3.00,28.88$ & 0.0001 \\
\hline Vimentin IHC & Negative vs. positive & 0.42 & $0.09,1.91$ & 0.26 & & & \\
\hline AXL/GAS6 classification & The others ${ }^{\mathrm{a}}$ vs. AXL ${ }^{+} / \mathrm{GAS}^{+}$ & 3.89 & $1.35,11.24$ & 0.012 & 5.90 & $1.88,18.53$ & 0.0024 \\
\hline
\end{tabular}

$\mathrm{HR}$, hazard ratio for death; CI, confidence interval; IHC, immunohistochemistry; ${ }^{a} \mathrm{AXL}^{+} / \mathrm{GAS6}^{-}$plus AXL-/GAS6 ${ }^{+}$plus AXL $/ \mathrm{GAS}^{-}$.

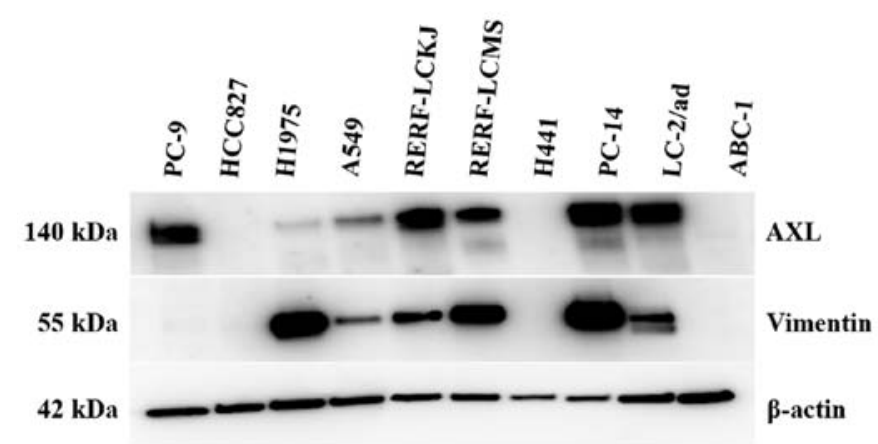

Figure 4. AXL and vimentin expression in 10 lung adenocarcinoma cell lines. Among seven AD cell lines with wild-type EGFR, five cell lines (A549, RERF-LC-KJ, RERF-LC-MS, PC-14 and LC-2/ad) showed positive expression for AXL and vimentin; however, two cell lines (H441 and ABC-1) showed neither AXL nor vimentin expression. Of three AD cell lines showing mutant EGFR, PC-9 and H1975 cells showed AXL or vimentin expression, respectively; however, HCC827 showed neither AXL nor vimentin expression.

analyses. Among stages I-III patients, $\mathrm{N}$ factor [hazard ratio $(\mathrm{HR})=2.94, \mathrm{P}=0.002]$, p-stage $(\mathrm{HR}=2.61, \mathrm{P}=0.007)$ and AXL/GAS6 classification ( $\mathrm{HR}=2.56, \mathrm{P}=0.011)$ were significant predictors of survival in univariate analysis (Table II). Multivariate analysis, adjusted for $\mathrm{N}$ factor, $\mathrm{p}$-stage, and AXL/GAS6 classification, showed that only AXL ${ }^{+} \mathrm{GAS}^{+}$
$(\mathrm{HR}=2.45, \mathrm{P}=0.018)$ was a statistically significant predictor of survival (Table II). In stage I cases, univariate analysis showed that the EGFR mutation status $(\mathrm{HR}=6.22, \mathrm{P}=0.001)$ and AXL/GAS6 classification $(\mathrm{HR}=3.89, \mathrm{P}=0.012)$ were significantly associated with death. Finally, the EGFR mutation status $(\mathrm{HR}=9.30, \mathrm{P}=0.0001)$ and $\mathrm{AXL} / \mathrm{GAS} 6$ classification $(\mathrm{HR}=5.90, \mathrm{P}=0.0024)$ were found to be independent predictors of death in multivariate analysis (Table II). Thus, co-expression of AXL and GAS6 significantly correlated with death for stages I-III and I lung AD patients.

AXL, GAS6, and vimentin expression in lung AD cell lines. We also evaluated protein expression levels of AXL, GAS6, and vimentin in 10 lung AD cell lines (Fig. 4). Unfortunately, GAS6 proteins were not detected in cells, probably because this is a secreted protein. Among seven AD cell lines with wild-type EGFR, five cell lines (A549, RERF-LC-KJ, RERF-LC-MS, PC-14, and LC-2/ad) strongly expressed AXL and vimentin protein. Of three mutant EGFR cell lines, PC-9 and H1975 showed strong AXL and vimentin expression, respectively.

\section{Discussion}

In this study, we found that the positive expression of AXL and GAS6 in combination could be used as a marker of a poor prognosis in lung AD patients. AXL protein expression has, 
in the past, correlated with lymph node metastasis and clinical stage $(13,25)$, while high expression levels of AXL and GAS6 have been associated with poor survival in lung AD patients with stage I-III (25). Consistent with these findings, we observed that AXL and GAS6 expression levels significantly correlated with poor survival in lung AD cases. Furthermore, we showed the negative impact that the high expression of both AXL and GAS6 had on the survival of patients with stage I lung AD. Of note, $\mathrm{AXL}^{+}$expression significantly correlated with vimentin ${ }^{+}$ expression, as reported in an earlier in vitro study (26). The co-expression of AXL and GAS6 was mostly associated with vimentin positive expression in this study. Thus, rather than the individual expression of either protein, the expression of both in combination may be more closely associated with the biological features of vimentin, suggesting that $\mathrm{AXL}^{+} / \mathrm{GAS}^{+}$tumor cells may represent abundant vimentin. Vimentin may actually induce AXL expression (27). However, vimentin expression was not a prognostic factor in this study. Besides vimentin, AXL expression could be also regulated by other factors, including TGF- $\beta 1$ (26). Therefore, AXL and GAS6 co-expression, but not vimentin expression, may be critical for patient survival, as well as in the carcinogenesis of lung AD. Furthermore, high vimentin expression correlated with an EGFR wild-type status. AXL and vimentin-positive expression were also found for most AD cell lines showing wild-type EGFR. Therefore, AXL and GAS6 may play a critical role in tumor progression and patient survival in lung AD patients with wild-type EGFR. As for the significance of AXL/GAS6/vimentin for the EGFR mutant-type, small numbers of stage I-III AD patients as well as AD cells with the EGFR mutation have been analyzed. Further studies are planned to perform using large-scale samples with an EGFR mutation, including stage IV, to evaluate the correlation between AXL/GAS6/vimentin expression and EGFR status as a prognostic factor.

Recently, AXL upregulation and activation by GAS6 has been implicated in the EMT of breast cancer and hepatocellular carcinoma $(28,29)$. Likewise, the expression of both AXL and GAS6 is deemed to be closely related to full-blown EMT in a subset of lung AD. AXL-related EMT resulting in drug resistance has been reported in patients with prior EGFR-TKI therapy, as well as in in vitro studies using NSCLC cell lines $(15,16,30)$. Aberrant AXL signaling and the development of the EMT phenotype were also associated with ALK inhibitor resistance in ALK-driven neuroblastoma cells (31). Our clinical data support the concept that EMT under AXL or GAS6 high expression apparently exists in patients with prior surgical resection for lung $\mathrm{AD}$, which consequently leads to de novo resistance to EGFR-TKI $(15,30)$.

Unfortunately, approximately $20-30 \%$ of early stage NSCLC patients undergo a relapse, even after complete surgical treatment (32). Sensitive biomarkers can help identify patients with early-stage or locally advanced NSCLC who have a high risk of relapse and a poor prognosis. High expression levels of excision repair cross-complementation group 1 (ERCC1), ribonucleotide reductase subunit M2 (RRM2), and thymidylate synthase (TS) were suggested as negative prognostic factors for patients with resected NSCLC $(33,34)$. In addition, cyclooxygenase- 2 and amplification of the actin-4 (ACTN4) gene were considered markers for a poor prognosis in stage I disease $(35,36)$. However, a conceivable prognostic biomarker for patients with stage I AD has not yet been established. In the present study, we demonstrated that the co-expression of AXL and GAS6 had a greater effect on survival in patients with stage I lung AD, especially in those with wild-type EGFR. AXL has been recognized as a potential therapeutic target for overcoming EGFR-TKI resistance (30). The BATTLE study using AXL inhibitor and EGFR-TKI demonstrated synergistic effects in some patients with wild-type EGFR (15). Our findings suggest that the combination of AXL and GAS6 was significantly associated with poor overall survival and DFS in the AD subgroup of stage I disease with wild-type EGFR. Therefore, AXL and GAS6 may be promising predictive biomarkers of a drug response and crucial therapeutic targets in lung AD with wild-type EGFR. The prognostic significance of the co-expression of AXL and GAS6 needs to be further validated in large-scale studies of AD samples. Further investigation is also needed to determine whether the overexpression of AXL and/or GAS6 modulate different internal signaling pathways, depending on the EGFR status and EMT signature.

Our study demonstrated that the co-expression of AXL and GAS6 in a tumor was a significant independent predictor of a poor outcome in patients with stage I lung AD, as well as stages I-III lung AD. An AXL and GAS6 expression status may be useful for the identification of lung AD patients at high risk of post-operative death and who will benefit from adjuvant chemotherapy.

\section{Acknowledgements}

This study was supported in part by a grant-in-aid from the Ministry of Education, Culture, Sports, Science, and Technology of Japan (grant no. 25461172 to A.G.), and the Clinical Rebiopy Bank Project for Comprehensive Cancer Therapy Development in Nippon Medical School.

\section{References}

1. Torre LA, Bray F, Siegel RL, Ferlay J, Lortet-Tieulent J and Jemal A: Global cancer statistics, 2012. CA Cancer J Clin 65: 87-108, 2015.

2. Alberg AJ, Brock MV, Ford JG, Samet JM and Spivack SD: Epidemiology of lung cancer: Diagnosis and management of lung cancer, 3rd ed: American College of Chest Physicians evidence-based clinical practice guidelines. Chest 143 (Suppl 5): e1-e29, 2013.

3. Maemondo M, Inoue A, Kobayashi K, Sugawara S, Oizumi S, Isobe H, Gemma A, Harada M, Yoshizawa H, Kinoshita I, et al; North-East Japan Study Group: Gefitinib or chemotherapy for non-small-cell lung cancer with mutated EGFR. N Engl J Med 362: 2380-2388, 2010

4. Mitsudomi T, Morita S, Yatabe Y, Negoro S, Okamoto I, Tsurutani J, Seto T, Satouchi M, Tada H, Hirashima T, et al; West Japan Oncology Group: Gefitinib versus cisplatin plus docetaxel in patients with non-small-cell lung cancer harbouring mutations of the epidermal growth factor receptor (WJTOG3405): An open label, randomised phase 3 trial. Lancet Oncol 11: 121-128, 2010.

5. Shaw AT, Kim DW, Nakagawa K, Seto T, Crinó L, Ahn MJ, De Pas T, Besse B, Solomon BJ, Blackhall F, et al: Crizotinib versus chemotherapy in advanced ALK-positive lung cancer. N Engl J Med 368: 2385-2394, 2013.

6. Hasanbasic I, Cuerquis J, Varnum B and Blostein MD: Intracellular signaling pathways involved in Gas6-Axl-mediated survival of endothelial cells. Am J Physiol Heart Circ Physiol 287: H1207-H1213, 2004.

7. Lee WP, Wen Y, Varnum B and Hung MC: Akt is required for Axl-Gas6 signaling to protect cells from E1A-mediated apoptosis. Oncogene 21: 329-336, 2002. 
8. Vajkoczy P, Knyazev P, Kunkel A, Capelle HH, Behrndt S, von Tengg-Kobligk H, Kiessling F, Eichelsbacher U, Essig M, Read TA, et al: Dominant-negative inhibition of the Axl receptor tyrosine kinase suppresses brain tumor cell growth and invasion and prolongs survival. Proc Natl Acad Sci USA 103: 5799-5804, 2006.

9. Lay JD, Hong CC, Huang JS, Yang YY, Pao CY, Liu CH, Lai YP, Lai GM, Cheng AL, Su IJ, et al: Sulfasalazine suppresses drug resistance and invasiveness of lung adenocarcinoma cells expressing AXL. Cancer Res 67: 3878-3887, 2007.

10. Linger RM, Keating AK, Earp HS and Graham DK: Taking aim at Mer and Axl receptor tyrosine kinases as novel therapeutic targets in solid tumors. Expert Opin Ther Targets 14: 1073-1090, 2010.

11. Hutterer M, Knyazev P, Abate A, Reschke M, Maier H, Stefanova N, Knyazeva T, Barbieri V, Reindl M, Muigg A, et al: Axl and growth arrest-specific gene 6 are frequently overexpressed in human gliomas and predict poor prognosis in patients with glioblastoma multiforme. Clin Cancer Res 14: 130-138, 2008.

12. Meric F, Lee WP, Sahin A, Zhang H, Kung HJ and Hung MC: Expression profile of tyrosine kinases in breast cancer. Clin Cancer Res 8: 361-367, 2002.

13. Shieh YS, Lai CY, Kao YR, Shiah SG, Chu YW, Lee HS and Wu CW: Expression of axl in lung adenocarcinoma and correlation with tumor progression. Neoplasia 7: 1058-1064, 2005.

14. Wu CW, Li AF, Chi CW, Lai CH, Huang CL, Lo SS, Lui WY and Lin WC: Clinical significance of AXL kinase family in gastric cancer. Anticancer Res 22: 1071-1078, 2002.

15. Byers LA, Diao L, Wang J, Saintigny P, Girard L, Peyton M, Shen L,Fan Y, Giri U, Tumula PK, et al: An epithelial-mesenchymal transition gene signature predicts resistance to EGFR and PI3K inhibitors and identifies Axl as a therapeutic target for overcoming EGFR inhibitor resistance. Clin Cancer Res 19: 279-290, 2013.

16. Zhang Z, Lee JC, Lin L, Olivas V, Au V, LaFramboise T, AbdelRahman M, Wang X, Levine AD, Rho JK, et al: Activation of the AXL kinase causes resistance to EGFR-targeted therapy in lung cancer. Nat Genet 44: 852-860, 2012.

17. Goldstraw P, Crowley J, Chansky K, Giroux DJ, Groome PA Rami-Porta R, Postmus PE, Rusch V and Sobin L; International Association for the Study of Lung Cancer International Staging Committee; Participating Institutions: The IASLC Lung Cancer Staging Project: Proposals for the revision of the TNM stage groupings in the forthcoming (seventh) edition of the TNM Classification of malignant tumours. J Thorac Oncol 2: 706-714, 2007.

18. Travis WD, Brambilla E, Noguchi M, Nicholson AG, Geisinger KR, Yatabe Y, Beer DG, Powell CA, Riely GJ, Van Schil PE, et al: International association for the study of lung cancer/american thoracic society/european respiratory society international multidisciplinary classification of lung adenocarcinoma. J Thorac Oncol 6: 244-285, 2011.

19. Edge S, Byrd DR, Compton CC, Fritz AG, Greene FL and Trotti A (eds): AJCC cancer staging manual. 7th edition. Springer, New York, NY, 2010

20. Nagai Y, Miyazawa H, Huqun, Tanaka T, Udagawa K, Kato M, Fukuyama S, Yokote A, Kobayashi K, Kanazawa M, et al: Genetic heterogeneity of the epidermal growth factor receptor in non-small cell lung cancer cell lines revealed by a rapid and sensitive detection system, the peptide nucleic acid-locked nucleic acid PCR clamp. Cancer Res 65: 7276-7282, 2005.

21. McCarty KS Jr, Miller LS, Cox EB, Konrath J and McCarty KS Sr: Estrogen receptor analyses. Correlation of biochemical and immunohistochemical methods using monoclonal antireceptor antibodies. Arch Pathol Lab Med 109: 716-721, 1985.

22. Hirano H, Maeda H, Takeuchi Y, Susaki Y, Kobayashi R, Hayashi A, Ose N, Yamaguchi T, Yokota S and Mori M Lymphatic invasion of micropapillary cancer cells is associated with a poor prognosis of pathological stage IA lung adenocarcinomas. Oncol Lett 8: 1107-1111, 2014.
23. Shimokawa T, Seike M, Soeno C, Uesaka H, Miyanaga A, Mizutani H, Kitamura K, Minegishi Y, Noro R, Okano T, et al: Enzastaurin has anti-tumour effects in lung cancers with overexpressed JAK pathway molecules. Br J Cancer 106: 867-875, 2012.

24. Seike M, Goto A, Okano T, Bowman ED, Schetter AJ, Horikawa I, Mathe EA, Jen J, Yang P, Sugimura H, et al: MiR-21 is an EGFRregulated anti-apoptotic factor in lung cancer in never-smokers. Proc Natl Acad Sci USA 106: 12085-12090, 2009.

25. Ishikawa M, Sonobe M, Nakayama E, Kobayashi M, Kikuchi R, Kitamura J, Imamura $\mathrm{N}$ and Date $\mathrm{H}$ : Higher expression of receptor tyrosine kinase Axl, and differential expression of its ligand, Gas6, predict poor survival in lung adenocarcinoma patients. Ann Surg Oncol 20 (Suppl 3): S467-S476, 2013.

26. Wilson C, Ye X, Pham T, Lin E, Chan S, McNamara E, Neve RM, Belmont L, Koeppen H, Yauch RL, et al: AXL inhibition sensitizes mesenchymal cancer cells to antimitotic drugs. Cancer Res 74: 5878-5890, 2014.

27. Vuoriluoto K, Haugen H, Kiviluoto S, Mpindi JP, Nevo J, Gjerdrum C, Tiron C, Lorens JB and Ivaska J: Vimentin regulates EMT induction by Slug and oncogenic $\mathrm{H}$-Ras and migration by governing Axl expression in breast cancer. Oncogene 30: 1436-1448, 2011

28. Gjerdrum C, Tiron C, Høiby T, Stefansson I, Haugen H, Sandal T, Collett K, Li S, McCormack E, Gjertsen BT, et al: Axl is an essential epithelial-to-mesenchymal transition-induced regulator of breast cancer metastasis and patient survival. Proc Natl Acad Sci USA 107: 1124-1129, 2010

29. Reichl P, Dengler M, van Zijl F, Huber H, Führlinger G, Reichel C, Sieghart W, Peck-Radosavljevic M, Grubinger M and Mikulits W: Axl activates autocrine transforming growth factor- $\beta$ signaling in hepatocellular carcinoma. Hepatology 61 : 930-941, 2015.

30. Wu F, Li J, Jang C, Wang J and Xiong J: The role of Axl in drug resistance and epithelial-to-mesenchymal transition of non-small cell lung carcinoma. Int J Clin Exp Pathol 7: 6653-6661, 2014.

31. Debruyne DN, Bhatnagar N, Sharma B, Luther W, Moore NF, Cheung NK, Gray NS and George RE: ALK inhibitor resistance in ALK-driven neuroblastoma is associated with AXL activation and induction of EMT. Oncogene 35: 3681-3691, 2016.

32. Asamura H, Goya T, Koshiishi Y, Sohara Y, Eguchi K, Mori M, Nakanishi Y, Tsuchiya R, Shimokata K, Inoue H, et al; Japanese Joint Committee of Lung Cancer Registry: A Japanese Lung Cancer Registry study: Prognosis of 13,010 resected lung cancers. J Thorac Oncol 3: 46-52, 2008

33. Grossi F, Dal Bello MG, Salvi S, Puzone R, Pfeffer U, Fontana V, Alama A, Rijavec E, Barletta G, Genova C, et al: Expression of ribonucleotide reductase subunit-2 and thymidylate synthase correlates with poor prognosis in patients with resected stages I-III non-small cell lung cancer. Dis Markers 2015: $302649,2015$.

34. Zheng Z, Chen T, Li X, Haura E, Sharma A and Bepler G: DNA synthesis and repair genes RRM1 and ERCC1 in lung cancer. N Engl J Med 356: 800-808, 2007.

35. Mascaux C, Martin B, Paesmans M, Berghmans T, Dusart M, Haller A, Lothaire P, Meert AP, Lafitte JJ and Sculier JP: Has Cox-2 a prognostic role in non-small-cell lung cancer? A systematic review of the literature with meta-analysis of the survival results. Br J Cancer 95: 139-145, 2006.

36. Noro R, Honda K, Tsuta K, Ishii G, Maeshima AM, Miura N, Furuta K, Shibata T, Tsuda H, Ochiai A, et al: Distinct outcome of stage I lung adenocarcinoma with ACTN4 cell motility gene amplification. Ann Oncol 24: 2594-2600, 2013. 